\title{
Tracionamento de incisivo central superior permanente impactado pela presença de um mesiodente: relato de caso
}

\author{
Traction of permanent maxillary central incisor impacted by the \\ presence of mesiodens: case report
}

\author{
Ana Carolina Del-Sarto Azevedo Maia* \\ Malu Oliveira Santos** \\ Francisco Xavier Paranhos Coêlho Simões s** $^{* *}$ \\ Sibeli Rodrigues ${ }^{* * * * *}$ \\ Tatiane Fernandes Novaes ${ }^{* * * * *}$ \\ José Carlos Pettorossi Imparato ${ }^{* * * * * * *}$
}

\section{Resumo}

Introdução: dentes supranumerários, como sugere o próprio nome, são aqueles que se desenvolvem nos ossos maxilares, além da série normal. Acredita-se que a etiologia esteja relacionada à hiperatividade da lâmina dentária, trauma ou mesmo hereditariedade. Esses dentes podem ser encontrados em qualquer área dos arcos dentários, sendo sua localização mais frequente na linha média da maxila, onde são chamados mesiodentes. A presença de dentes supranumerários pode causar diversas desordens locais, incluindo retardo na erupção ou impacção de dentes adjacentes, diastemas, apinhamentos, giroversões, erupções ectópicas, reabsorções radiculares e formação de cistos. Ojetivo: este trabalho objetiva relatar um caso clínico de remoção cirúrgica de um mesiodente, mediante relativa frequência do achado de supranumerários desse tipo, discussões e relatos que envolvam a necessária abordagem clínica, desde o momento diagnóstico até o planejamento da conduta terapêutica ganham relevância.

Relato de caso: neste trabalho, será apresentado um caso clínico de remoção cirúrgica de um mesiodente diagnosticado em um paciente de 10 anos de idade e que provocava a impacção de um incisivo permanente. A remoção cirúrgica do supranumerário foi realizada sendo, imediatamente, colado um botão na coroa do incisivo impactado para que fosse feito o seu tracionamento. O paciente foi acompanhado até a completa irrupção do elemento 21 e seu realinhamento no arco. Concluímos que exames de rotina criteriosos e utilização, quando indicada, de exames complementares são fundamentais para adequada abordagem diagnóstica e terapêutica quando identificada a ocorrência de um mesiodente.

Palavras-chave: Dente supranumerário. Dente impactado. Cirurgia bucal. Ortodontia corretiva.

\section{Introdução}

Dentes supranumerários são aqueles que se desenvolvem além da série normal ${ }^{1-9}$. Sua etiologia ainda não está bem elucidada, mas acredita-se que esteja relacionada à hiperatividade da lâmina dentária, traumatismo ou mesmo hereditariedade ${ }^{4,6,7,9-14}$. Esses dentes podem ser encontrados em qualquer área dos arcos dentais, sendo que a localização mais frequente é na linha média da maxila, entre os incisivos centrais, onde são chamados mesiodentes ${ }^{3,6-12,14,15}$.

Mestranda em Odontopediatria pelo Centro de Pesquisas Odontológicas São Leopoldo Mandic; Professora da disciplina de Odontopediatria da Universidade Estadual do Sudoeste da Bahia - Uesb, Departamento de Saúde I, Jequié, BA, Brasil.

Acadêmica do Curso de Odontologia da Universidade Estadual do Sudoeste da Bahia - Uesb, Departamento de Saúde I, Jequié, BA, Brasil.

Doutor em Odontopediatria pela Universidade de São Paulo - USP; Professor da disciplina de Odontopediatria da Universidade Estadual do Sudoeste da Bahia - Uesb, Departamento de Saúde I, Jequié, BA, Brasil.

*** Especialista em Ortodontia Corretiva e Interceptativa pela Faculdade de Odontologia da Fundação Educacional de Barretos, SP, Brasil.

****** Pós-doutoranda em Odontopediatria pela Universidade Cruzeiro do Sul -Unicsul, São Paulo, SP, Brasil.

****** Professor do Programa de Pós-Graduação do Centro de Pesquisas Odontológicas São Leopoldo Mandic e Livre Docente da disciplina de Odontopediatria da Fousp, São Paulo, SP, Brasil. 
A ocorrência de dentes supranumerários é mais comum na dentição permanente, com prevalência variante entre $0,1-3,6 \%$ na dentição permanente e 0,2-1,9\% na decídua $a^{2,6-10,16}$. Além disso, são mais frequentes entre os indivíduos do sexo masculino, numa relação de prevalência em meninos e meninas de $2: 1^{2,3,6,8,10,11,13,15}$.

De acordo com sua morfologia, os mesiodentes podem ser classificados como cônicos (formato cônico), suplementares (com forma e tamanho similar aos da série) ou tuberculares (com forma totalmente diferente aos da série), mas, em sua maioria, são cônicos e menores que os incisivos maxilares normais ${ }^{2,7,9,11,12,15}$. Em relação à sua localização e direção, a maioria dos mesiodentes encontram-se invertidos na região palatina ${ }^{6,11}$.

Mesiodentes podem erupcionar normalmente, mas, em sua maioria encontram-se impactados, podendo estar associados a diversas complicações, incluindo retardo na erupção ou impacção de dentes adjacentes, diastemas, apinhamentos, giroversões, erupções ectópicas, reabsorções radiculares e for-

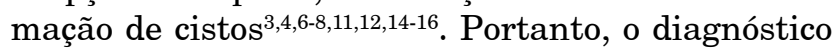
oportuno, em momento adequado deve ser feito por meio de observações clínicas e, quando necessário, radiográficas ${ }^{4,14}$.

Considerando que apenas $25 \%$ dos mesiodentes erupcionam normalmente ${ }^{9}$, clinicamente, suspeita-se de sua presença quando há assimetria no padrão de erupção dos incisivos superiores, retenção prolongada dos incisivos decíduos ${ }^{16}$ ou, ainda, quando há um acentuado desvio na erupção de um ou de ambos incisivos centrais permanentes ${ }^{9}$. O correto diagnóstico é obtido por meio de exame clínico cuidadoso (inspeção e palpação) e complementado por radiografias ${ }^{16}$ panorâmicas, periapicais, oclusais de maxi$\mathrm{la}^{9,15}$ e tomografia computadorizada $\mathrm{a}^{17-19}$ confirmando a presença e a localização do supranumerário ${ }^{16}$.

A conduta frente à presença de um mesiodente é variável. A exodontia do supranumerário, associada ou não a outras formas de tratamento, é sugerida em $88,1 \%$ dos $\operatorname{casos}^{12}$. No entanto, o momento mais oportuno para a exodontia deve ser avaliado, pois a remoção do mesiodente em idade precoce pode pôr em risco o desenvolvimento do germe permanente, caso ocorra uma lesão acidental ${ }^{16}$. Quando o mesiodente não causa problemas aos dentes vizinhos e/ ou o paciente é muito jovem, pode-se aguardar o término da rizogênese dos dentes adjacentes, mas realizando acompanhamentos clínico e radiográfico periódicos ${ }^{12,16}$. A exposição cirúrgica da coroa do incisivo central é indicada quando esse não irrompe espontaneamente após seis meses da remoção do supranumerário, considerando que o tracionamento ortodôntico é sugerido como recurso para trazer o dente para a cavidade bucal ${ }^{12,16}$.

Conhecidas essas variedades de apresentação, necessidade e oportunidade cirúrgica para remoção de um mesiodente, discussões sobre o tema tornam-se importantes para informar e favorecer o desen- volvimento de um olhar atendo e assertiva diagnóstica a ser dada pelo cirurgião-dentista. Assim, o presente artigo objetiva relatar um caso clínico de remoção cirúrgica de um mesiodente diagnosticado em um paciente de 10 anos de idade e responsável pela impactação de um incisivo permanente que fora tracionado ortodonticamente.

\section{Relato de caso}

Paciente do sexo masculino, de 10 anos e 11 meses de idade, acompanhado do responsável, compareceu à Clínica Odontopediátrica da Faculdade de Odontologia da Universidade Estadual do Sudoeste da Bahia (Uesb) já orientado previamente por outro profissional sobre a presença de um dente supranumerário (mesiodente) que se relacionava à ausência do incisivo central superior esquerdo permanente (elemento 21), impactado pela presença do mesiodente.

$\mathrm{Na}$ anamnese não foi constatada alteração na saúde geral do paciente. No exame clínico, não foram observadas lesões cariosas ou problemas periodontais. No entanto, o elemento 21 não se encontrava no arco dentário (Figura 1).

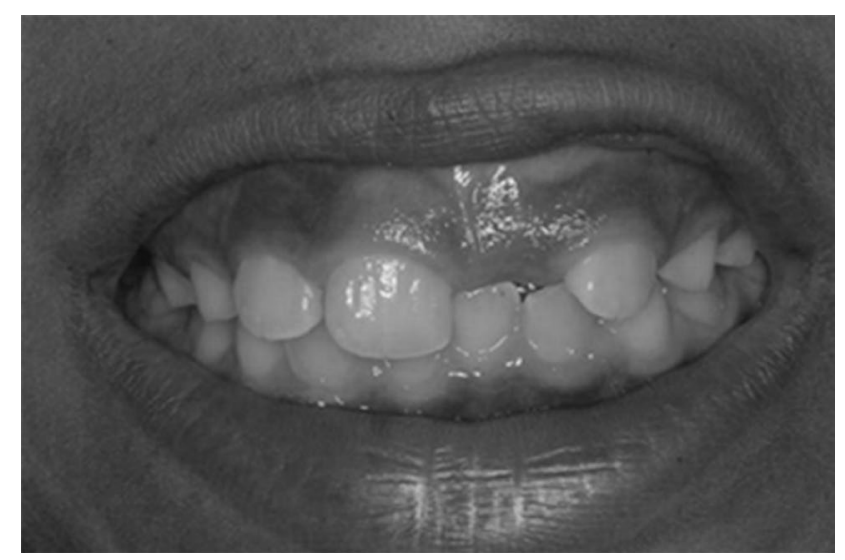

Figura 1 - Vista frontal do paciente, ao exame clínico inicial, confirmando ausência do elemento 21 no arco dentário

A análise das radiografias panorâmica (Figura 2A) e periapical (Figura 2B), bem como da tomografia computadorizada (Figura 3A), confirmou a presença de um mesiodente, causando a impacção do elemento 21. As imagens tomográficas confirmaram sua localização por palatino (Figura 3B). 


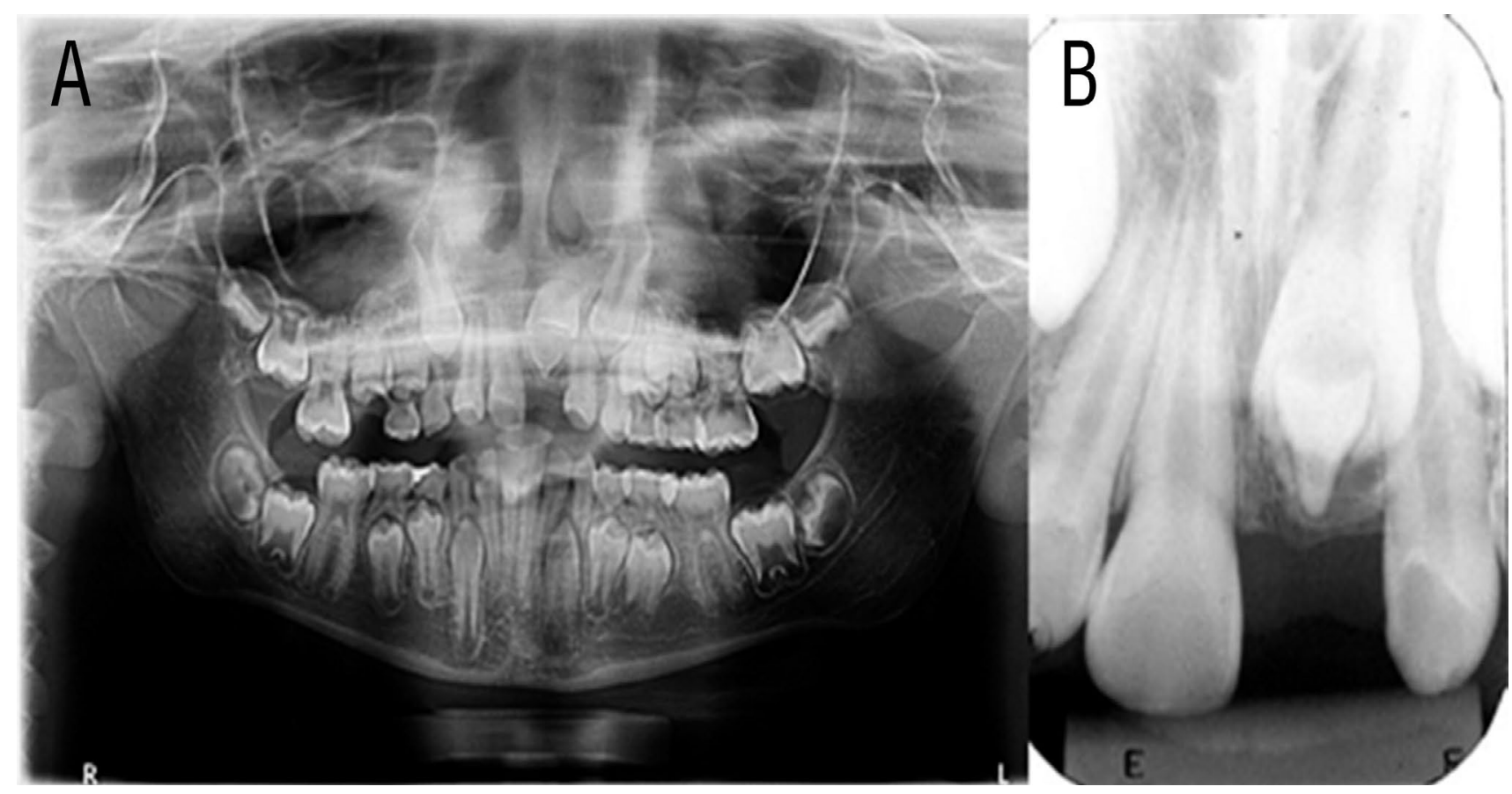

Figura 2 - Radiografia panorâmica evidenciando a presença de mesiodente (A), assim como radiografia periapical, confirmando a impacção do elemento 21, devido ao mesiodente (B)

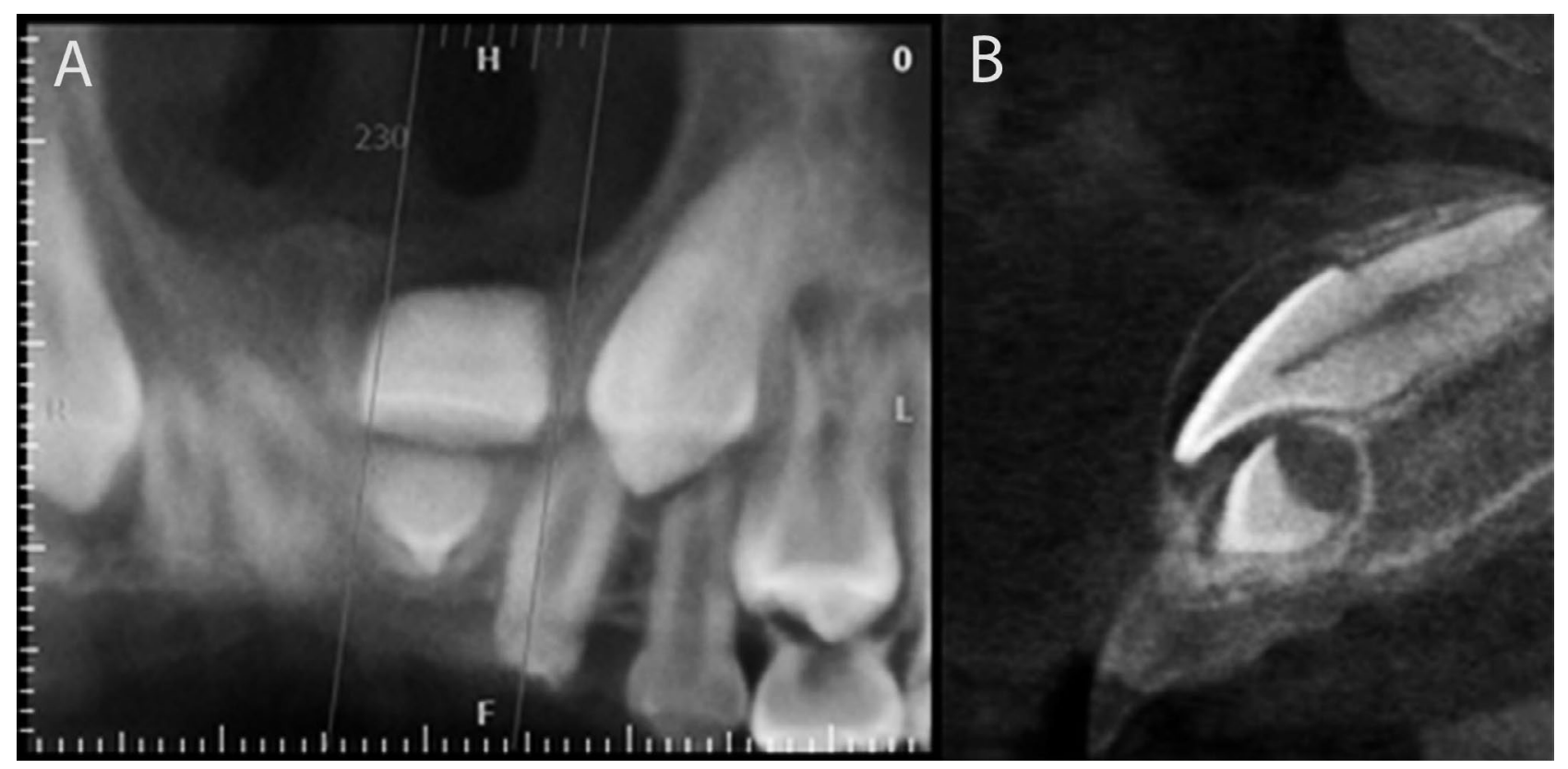

Figura 3 - Imagens tomográficas (A e B), evidenciando a localização por palatina do elemento supranumerário

Foram solicitados exames pré-operatórios e, na semana seguinte, após confirmação da integridade sistêmica do paciente, foi realizada a remoção cirúrgica do supranumerário, com anestesia local infiltrativa, seguida da papilar e complementada por palatina, utilizando como anestésico a lidocaína $2 \%$ com epinefrina1:100000 (Alphacaine, DFL ${ }^{\circledR}$, Rio de Janeiro, RJ, Brasil). A técnica cirúrgica envolveu a realização de incisão de Newman, utilizando lâmina de bisturi no 11 (Figura 4A) seguida do descolamento e o rebatimento do retalho (Figura 4B). Devido à presença de tecido ósseo recobrindo o mesiodente, foi feita a osteotomia (Figura 5A) com turbina e broca de alta rotação 1014 (KG Sorensen ${ }^{\circledR}$, Nova
Iorque, Nova Iorque, USA) sobre intensa refrigeração com solução salina estéril até a sua visualização (Figura 5B) e posterior remoção (Figura 5C). Foi realizada curetagem cuidadosa, para remoção de possíveis espículas ósseas, irrigação abundante com solução salina e hemostasia da ferida cirúrgica com gaze estéril. Em seguida, procedeu-se à colagem de um botão metálico, dispositivo ortodôntico necessário para o tracionamento do elemento 21 , com resina composta fotoativada (Z350 Filtek 3M ESPE ${ }^{\circledR}$, Maplewood, Minnesota, USA), seguindo a recomendação do fabricante para a realização da técnica. Ao fim, foi feita a sutura do retalho com pontos simples e fio de seda 4.0 (Figura 5D). 


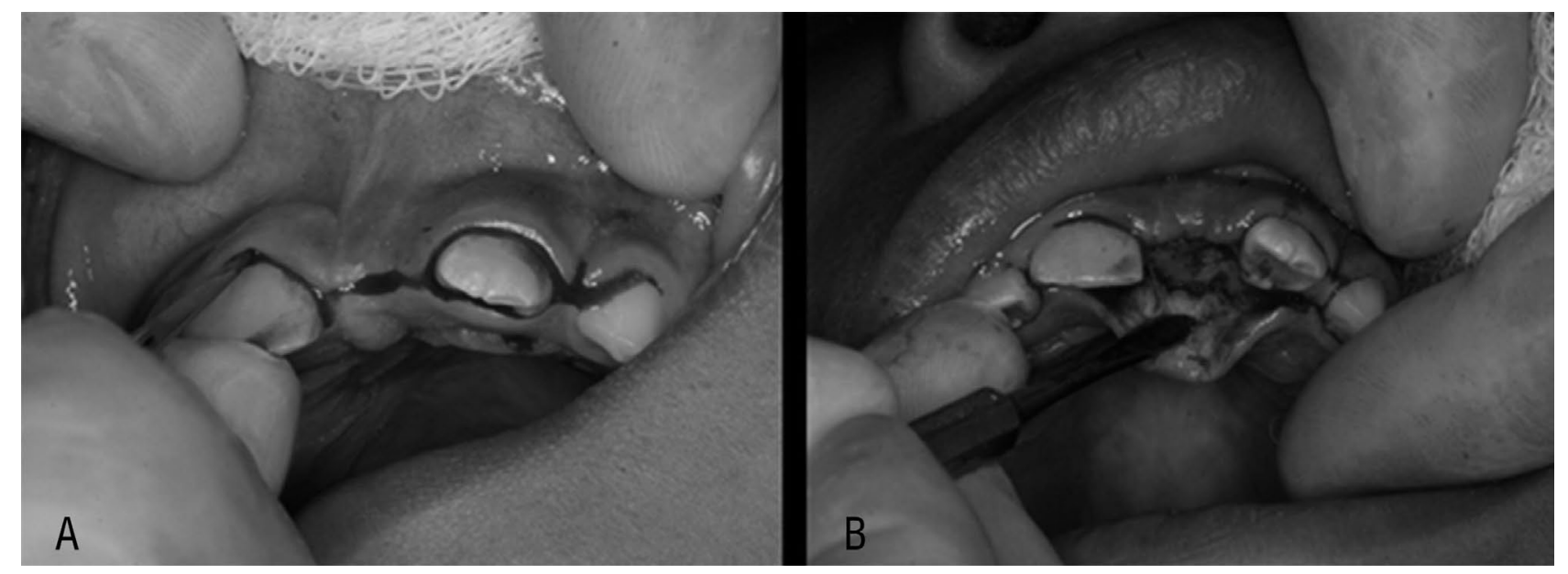

Figura 4 - Realização de incisão (A). Descolamento e rebatimento do retalho (B)

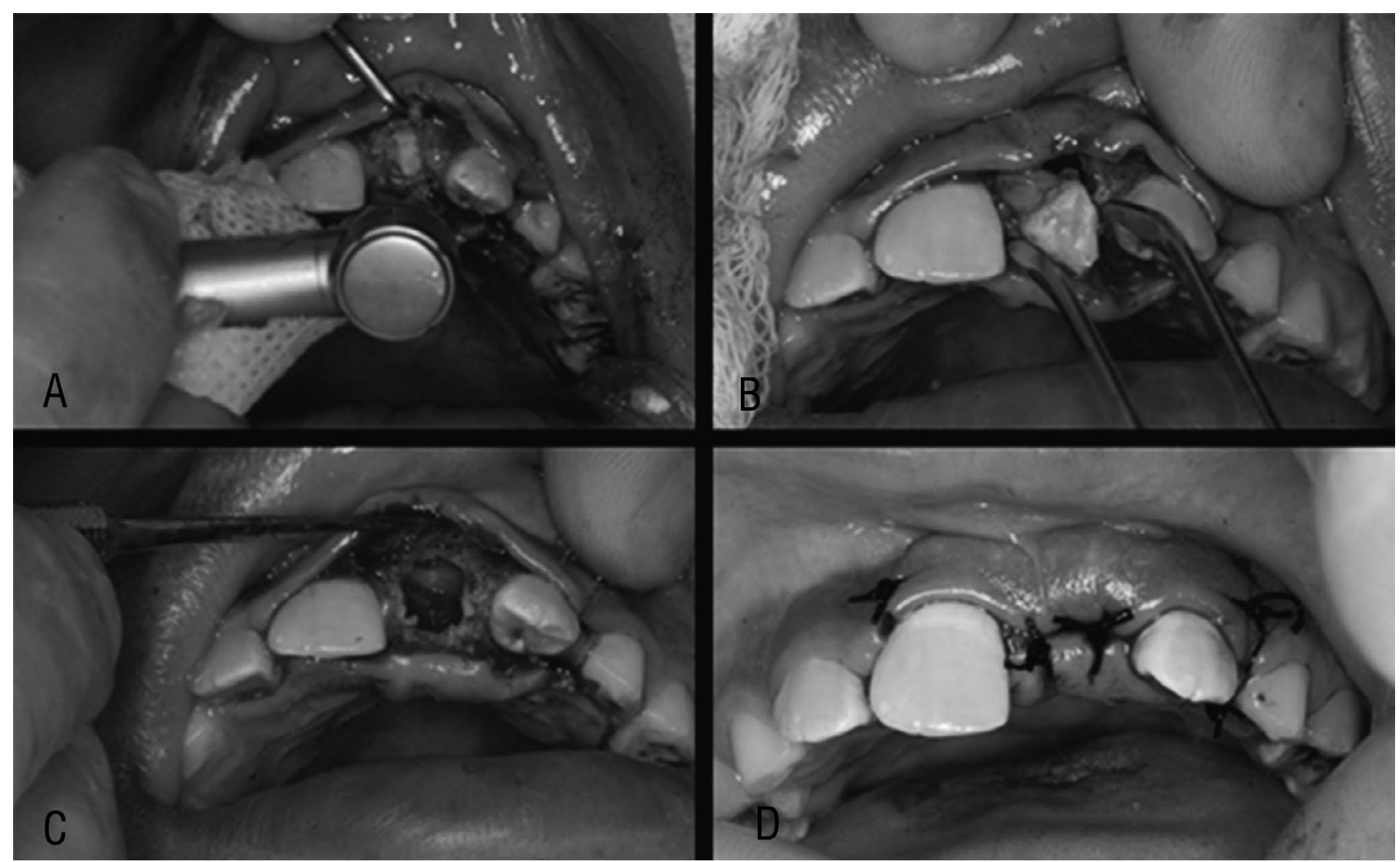

Figura 5 - Osteotomia (A). Remoção do mesiodente (B). Loja cirúrgica (C). Sutura após a colagem do dispositivo ortodôntico para tracionamento do elemento $21(D)$

Após uma semana, o paciente retornou para que a sutura fosse removida (Figura $6 \mathrm{~A}$ ). Na semana seguinte, foi instalado aparelho ortodôntico removível para o tracionamento do elemento 21 com elástico de látex $5 / 16$ polegadas e força de 130 gramas Morelli ${ }^{\circledR}$ (Figura 6B). As consultas de manutenção eram realizadas semanalmente, quando era feita a troca do elástico ortodôntico e o acompanhamento clínico do tracionamento. Ao fim de dois meses, o elemento dentário irrompeu pela face vestibular no arco e, então, o aparelho foi removido. Durante todo esse período, o paciente não apresentou queixa de dor, apenas um leve desconforto na última semana que antecedeu o surgimento da unidade dentária. 


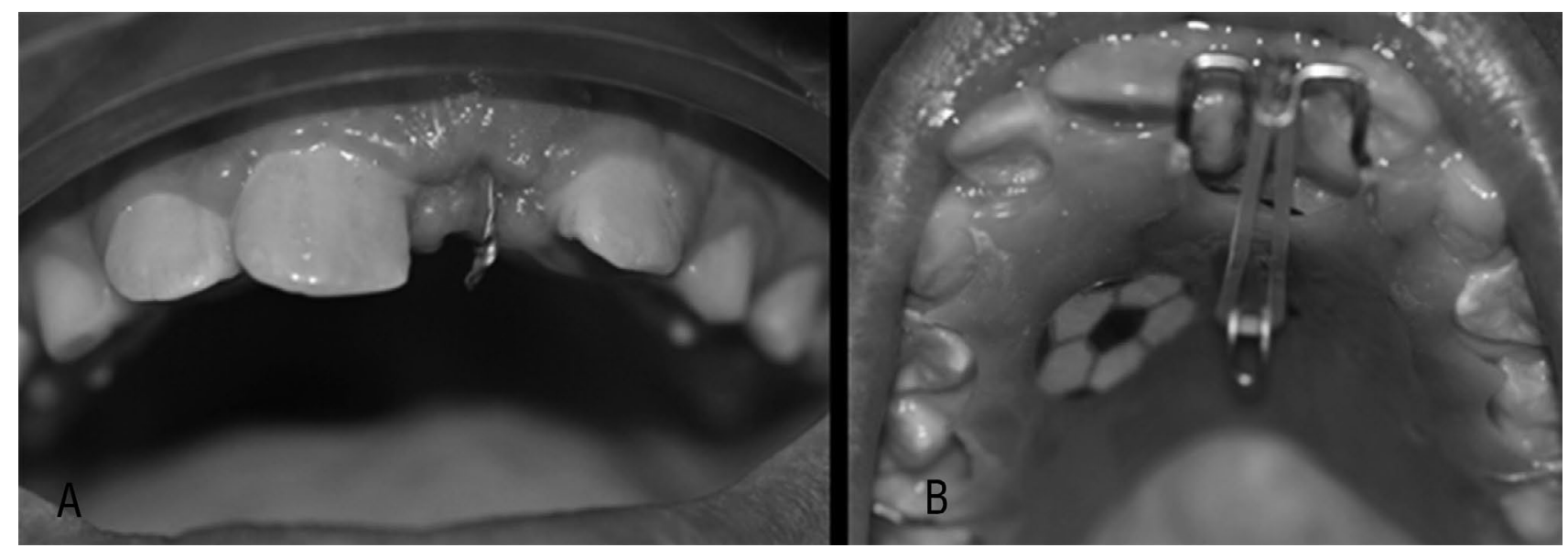

Figura 6 - Imagem após remoção da sutura, evidenciando o fio para o tracionamento (A). Aparelho ortodôntico removível utilizado para a movimentação do elemento 21 (B)

O paciente deixou de frequentar as consultas e, cerca de seis meses depois, compareceu ao consultório odontológico, quando foi programada a instalação de aparelho ortodôntico fixo para alinhamento. O paciente permaneceu em manutenção ortodôntica por cerca de nove meses quando, mais uma vez, deixou de frequentar as consultas marcadas até que nos fosse informado pelo seu responsável necessidade de interrupção do tratamento, por razões pessoais (Figura 7).

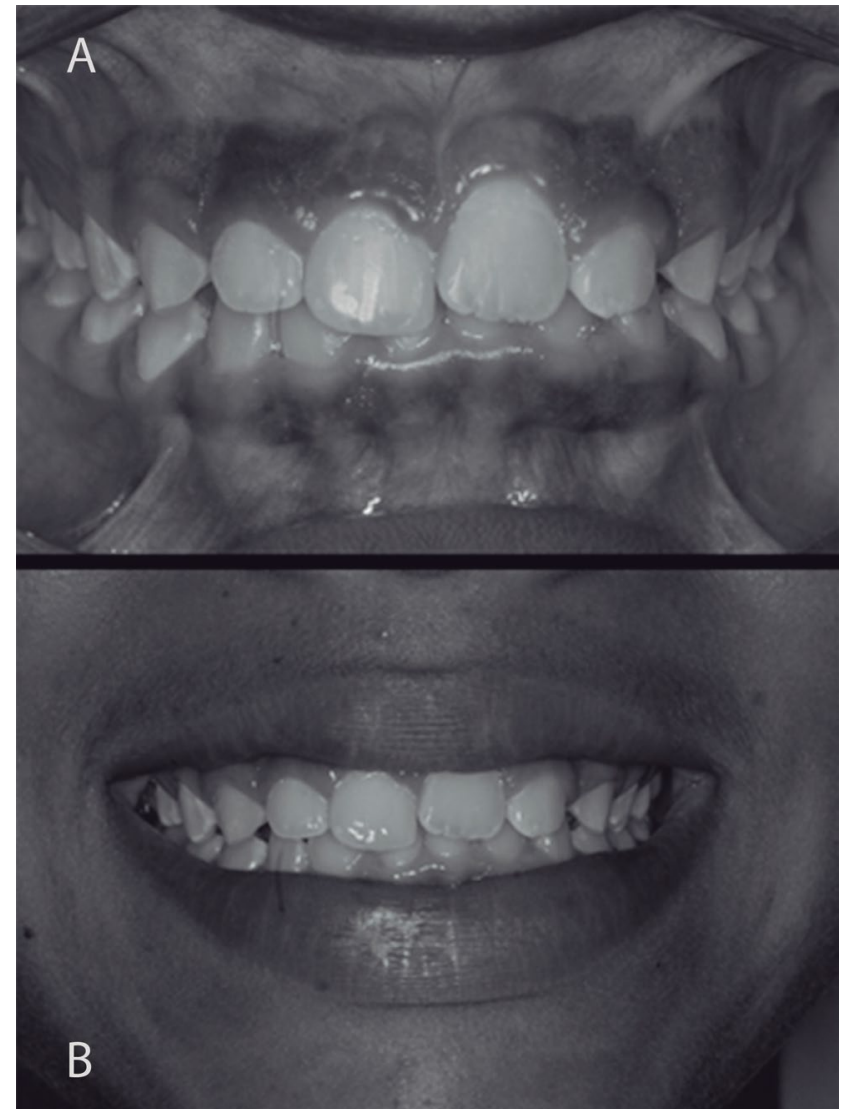

Figura 7 - Vista frontal evidenciando o elemento 21 posicionado no arco dentário (A). Imagem do aspecto final do sorriso do paciente (B)

\section{Discussão}

Os mesiodentes frequentemente interferem na erupção e no alinhamento dos incisivos maxilares ${ }^{9}$, estando relacionados a diversas desordens locais, que incluem retardo na erupção ou na impacção de dentes adjacentes ${ }^{3,4,6-8,11,12,14-16}$ como observado no caso relatado. Portanto, o diagnóstico em momento oportuno e a intervenção adequada são de suma importância para um tratamento conservador e um melhor prognóstico, podendo evitar ou minimizar problemas estéticos, funcionais e psicológicos.

No caso descrito, estando o paciente em idade avançada, o atraso na erupção do incisivo central superior esquerdo chamou a atenção e levou a suspeita da presença de um mesiodente ${ }^{9,16}$ não observado clinicamente na cavidade bucal. Essa descrição corrobora com o achado de que apenas $25 \%$ dos mesiodentes conseguem irromper normalmente ${ }^{9}$.

O diagnóstico adequado da presença de um mesiodente pode ser obtido por meio de cuidadosa inspeção e palpação da região, bem como um olhar atento ao desenvolvimento e a cronologia de erupção dentária a serem feitos nas consultas odontológicas de rotina. Só então, frente à suspeita ou à identificação de qualquer alteração, exames complementares imaginológicos, como as radiografias ${ }^{9,15,16} \mathrm{e}$, mais recentemente, as tomografias computadorizadas ${ }^{17-19}$, podem ser indicados.

No presente relato, a presença de um supranumerário impactado foi detectada tardiamente, pois o paciente já se encontrava em idade avançada com evidente retardo na erupção de um incisivo permanente. Foi assim que, somente aos dez anos de idade, foi identificada a impacção do elemento 21 causada pela presença de um mesiodente. Acreditamos que, em consultas odontológicas de rotina realizadas dos 6 aos 7 anos de idade, a identificação de um incisivo superior em movimento eruptivo habitual acompanhado pela não irrupção do seu homólogo deveria ter sido identificada, justificando 
também a necessidade dos exames de imagem complementares. No presente caso, o diagnóstico tardio pode ter sido ocasionado pelo não comparecimento do paciente em consultas odontológicas de rotina indicadas semestral ou anualmente, ou também por negligência e incorretas avaliações clínicas feitas por um profissional despreparado.

As radiografias panorâmicas oferecem uma visão geral das arcadas dentárias, no entanto, a falta de clareza na região da linha média pode limitar a visualização do mesiodente $e^{4,9,20}$. Além disso, não fornecem informações quanto ao posicionamento vestíbulo-lingual do supranumerário ${ }^{18}$. Dessa forma, a obtenção de radiografias periapicais e oclusais de maxila possibilita uma melhor identificação da direção de erupção e a localização do mesiodente impactado e sua relação com as estruturas adjacentes, permitindo a elaboração de um adequado planejamento cirúrgico ${ }^{9}$.

As tomografias computadorizadas, por sua vez, possibilitam visualizar com maior precisão os limites do supranumerário e sua relação com as estruturas anatômicas adjacentes, bem como sua localização por vestibular ou palatina, além de fornecer imagens menos distorcidas do que as radiografias odontológicas convencionais ${ }^{18,19}$. No caso apresentado, as radiografias periapicais e a tomografia, complementares ao exame panorâmico, favoreceram a completa caracterização do mesiodente identificado ainda incluso no palato, facilitando também a terapêutica cirúrgica.

A remoção da unidade supranumerária fez-se necessária, pois sua presença impedia a irrupção do incisivo central superior esquerdo permanente. Além disso, o momento cirúrgico foi oportuno, uma vez que os ápices radiculares dos dentes permanentes adjacentes encontravam-se fechados, afastando a possibilidade de lesões acidentais e prováveis danos à sua formação. Assim, alguns autores salientam que, quando não há alteração na cronologia de erupção de qualquer unidade devemos optar por uma abordagem mais conservadora, retardando a remoção do supranumerário até que o processo de rizogênese dos dentes vizinhos se complete ${ }^{12,16}$.

A extração de mesiodentes na dentição decídua, em geral, não é recomendada. Isso ocorre porque é grande o risco de deslocar ou danificar o germe do dente sucessor permanente ${ }^{9,16}$. No entanto, a remoção do supranumerário na fase de dentição mista é preconizada na maioria dos casos, porque existem forças eruptivas normais capazes de promover a erupção espontânea dos incisivos permanentes impactados $^{9}$, minimizando a necessidade de tracionamento ortodôntico.

Intervenções tardias quando os ápices dos incisivos centrais inclusos estão parcialmente fechados, por volta dos 10 anos de idade, estão associadas a maiores complicações. Isso acontece porque, nesse momento, as forças que promovem a erupção normal dos incisivos estão diminuídas, logo, esses dentes não conseguem irromper espontaneamente, havendo necessidade de uma intervenção ortodôntica $^{9,12}$. Assim, quando a irrupção espontânea de dentes inclusos com rizogênese completa não acontecer, mesmo quando o diagnóstico tenha sido feito em momento adequado, torna-se necessária a remoção dos fatores etiológicos locais acompanhada da observação e garantia de que o perímetro da arcada tenha sido preservado ${ }^{21,22}$.

No caso descrito, o paciente apresentava espaço adequado para a irrupção da unidade dentária impactada. No entanto, após a remoção do fator etiológico local (nesse caso, o mesiodente), optamos pela utilização de dispositivos ortodônticos destinados ao tracionamento dentário pelo fato de o paciente já demonstrar os ápices dos incisivos praticamente fechados, com força de erupção provavelmente diminuída. Outro fator que nos direcionou à tomada de decisão pela instalação imediata do dispositivo ortodôntico foi o fato de se poder, com isso, evitar submeter o paciente a um segundo momento cirúrgico caso o dente não conseguisse fazer a sua irrupção espontânea.

Diversos autores obtiveram sucesso no tratamento de incisivos impactados pela exposição adequada da coroa associada ao tracionamento ortodôntico ${ }^{21-23}$. Entretanto, é válido destacar que o tratamento exige cuidados, pois é grande o risco de o tracionamento provocar recessão gengival, resultando em aumento de coroa clínica, ou, ainda, provocar necrose pulpar, anquilose ou reabsorção radicular $^{21}$, que podem surgir frene ao uso de forças ortodônticas excessivas, situação que não se aplicou ao caso relatado.

É importante salientar que, quanto mais osso for removido durante a exposição cirúrgica do dente incluso, maior será a perda óssea após o tratamento ortodôntico, o que resultará em aumento da coroa clínica e, consequentemente, um aspecto antiestético $^{21,23}$. No caso apresentado, a osteotomia foi mínima, suficiente apenas para expor uma face da coroa, possibilitando a colagem do botão ortodôntico para realização do tracionamento dentário.

O tracionamento dentário propriamente dito pode ser realizado por meio de aparelhos ortodônticos fixos ${ }^{23}$ ou removíveis ${ }^{21,22}$. O uso dos aparelhos fixos está indicado nos casos de pacientes com dentadura permanente completa e que apresentam outros problemas ortodônticos que podem ser corrigi$\operatorname{dos}^{22}$. No caso descrito, optou-se pela utilização de aparelho removível que, embora dependa da colaboração do paciente ${ }^{22}$, mostra-se vantajoso por ser um método relativamente simples e de baixo custo ${ }^{21}$, mas que, sobretudo, apresenta resultados satisfatórios, e de curto prazo. Os aparelhos removíveis só são indicados quando há espaço suficiente no arco para o tracionamento do elemento impactado e quando o elemento a ser tracionado estiver bem posicionado (verticalmente) ${ }^{21}$. Em todos os casos, o 
controle adequado da força ortodôntica utilizada é indispensável ${ }^{21,22}$.

$\mathrm{Na}$ finalização do caso, após o tracionamento dentário, feito com aparelho removível, foi feita a colagem de brackets nos incisivos para realizar o correto alinhamento de todas as unidades presentes. Nesses casos, o prognóstico é favorável ${ }^{21}$ e, além disso, o paciente apresentava um padrão periodontal satisfatório após o tracionamento dentário, com bom contorno gengival e sem perdas significativas de gengiva inserida e/ou osso. A resposta ao tratamento foi satisfatória, apesar da falta de colaboração do paciente, que não comparecia com regularidade às consultas de manutenção. Assim, o problema foi resolvido do ponto de vista funcional, estético e psicológico, com notável melhora na autoestima e na autoconfiança do paciente.

\section{Conclusão}

Concluímos que, sempre que identificada a ocorrência de um mesiodente, independentemente da técnica cirúrgica e da opção ortodôntica utilizada, mediante prováveis sequelas relacionadas, o mais importante é o profissional adotar na sua prática clínica exames de rotina criteriosos e a utilização, quando indicada, de exames complementares, para adequada abordagem diagnóstica e terapêutica.

\section{Abstract}

Introduction: supernumerary teeth, as the name suggests, are those that develop in upper jawbones, in addition to the normal series. It is believed that the etiology is related to hyperactivity of the dental lamina, trauma or even heredity. These teeth can be found in any area of the dental arches, and their most common location is midline of the maxilla, where they are called mesiodens. The presence of supernumerary teeth may cause several local disorders, including delayed eruption or impaction of adjacent teeth, diastemas, crowding, rotations, ectopic eruptions, root reabsorption, and formation of cysts. Objective and case report: this study aims to report a clinical case of surgical removal of mesiodens diagnosed in a 10-year-old patient, which caused the impaction of a permanent incisor. Surgical removal of the supernumerary was performed and a button was immediately bonded to the crown of the impacted incisor so to allow its traction. The patient was followed until complete eruption of element 21 and its realignment in the arch. Final considerations: we conclude that strict routine examinations and the use - when recommended - of additional tests are essential for proper diagnostic and therapeutic approach when identifying the occurrence of mesiodens.

Keywords: Supernumerary tooth. Impacted tooth. Oral surgery. Corrective orthodontics.

\section{Referências}

1. Spyropoulos ND, Patsakas AJ, Angelopoulos AP. Simultaneous presence of partial anodontia and supernumerary teeth. Oral Surg Oral Med Oral Pathol 1979;48(1):53-6.

2. Küchler EC, Da Costa EG, Costa MC, Vieira AR, Granjeiro JM. Supernumerary teeth varydepending on gender. Braz Oral Res 2011;25(1):76-9.

3. Machado AW, Ambrosio AR, Caldas SGFR, Gandini Júnior LZ. Orthodontic treatment of a midline diastema related to mesiodens and thumb-sucking habit. Rev Odonto Ciênc 2010;25(3):314-8.

4. Simões FXPC, Crusoé-Rebello I, Neves FS, Oliveira-Santos C, Ciamponi AL, Da Silva Filho OG. Prevalence of supernumerary teeth in orthodontic patients from Southwestern Brazil. Int J Odontostomatol 2011;5(2):199-202.

5. Anthonappa RP, King NM, Rabie ABM. Diagnostic tools used to predict the prevalence of supernumerary teeth: a meta-analysis. Dentomaxillofac Radiol 2012;41:444-9.

6. Hong J, Lee DG, Park K. Retrospective analysis of the factors influencing mesiodentes eruption. Int J Paediatr Dent 2009;19:343-8.

7. Mukhopadhyay S. Mesiodens: A clinical and radiographic study in children. J Indian Soc Pedod Prev Dent 2011;29(1):34-8.

8. Khandelwal V, Nayak AU, Naveen RB, Ninawe N, Nayak PA, Sai Prasad SV. Prevalence of mesiodens among six-to seventeen-year-old school going children of Indore. J Indian Soc Pedod Prev Dent 2011;29(4):288-93.

9. Russell KA, Folwarczna MA. Mesiodens - diagnosis and management of a common supernumerary toothJ Calif Dent Assoc 2003;69(6):362-6.

10. Sycaras SN. Mesiodens in primary and permanent dentitions. Oral Surg Oral Med Oral Pathol 1975;39(6):870-4.

11. Hyun HK, Lee SJ, Lee SH, Hahn SH, Kim JW. Clinical Characteristics and Complications Associated With Mesiodentes. J Oral Maxillofac Surg 2009;67:2639-43.

12. Cachapuz PF, Siqueira FS, Prietsch JR. Tratamento ortodôntico interceptativo de maloclusão causada por mesiodente: relato de caso. Rev Fac Odontol Porto Alegre 2002;43(1):18-22.

13. Gallas MM, García A. Retention of permanent incisors by mesiodens: a family affair. Br Dent J 2000;88(2):63-4.

14. Alaçam A, Bani M. Mesiodens as a risk factor in treatment of trauma cases. Dent Traumatol 2009;25:25-31.

15. Günduz K, Çelenk P, Zengin Z, Sümer P. Mesiodens: a radiographic study in children. J Oral Sci 2008;50(3):287-91.

16. Rocha SCC, Vidigal BL, Fonseca MS, Manzi FR. Etiologia, Diagnóstico e Tratamento do Mesiodens - Relato de Caso Clínico Atípico. Arq Bras Odontol 2012;8(2):49-54.

17. Azenha MR, Zorzetto DLG, Marzola C, Moura LA, Handem RH. Abordagem Cirúrgica de Dente Supranumerário (Mesiodens) na Região Palatina: Caso Clínico. Rev Port Estomatol Cir Maxilofac 2007;48(1):37-41.

18. Lima ILA, Silva AIV, Oliveira FJ, Cardoso FO, Manzi FR. Radiografias convencionais e tomografia computadorizada cone-beam para localização de dentes inclusos: relato de caso. Arq Bras Odontol 2009;52:58-64.

19. Tochetto Primo B, Andrade MGS, Oliveira HW, Oliveira MG. Dentes retidos: novas perspectivas de localização. Rev Fac Odontol Univ Passo Fundo 2011;16(1):95-9.

20. Anthonappa RP, King NM, Rabie ABM, Mallineni SK. Reliability of panoramic radiographs for identifying supernumerary teeth in children. Int J Paediatr Dent 2012;22:37-43. 
21. Noronha MP, Stuani AS, Stuani MBS, Sant'anna EF. Tracionamento ortodôntico do incisivo central superior: relato de caso clínico. J Bras Ortodon Ortop Facial 2002;7(40):339-43.

22. Vianna AP, Monini AC, Machado AW, Gandini Júnior LG. Alternativa de tratamento simplificado e integrado da retenção intraóssea de incisivo central superior, associada a odontoma: relato de caso. Arch Health Invest 2012; 21(56):484-8.

23. Massa C de O. Tracionamento de incisivo central superior: relato de caso clínico [Monografia]. Brasília: Programa de Especialização em Ortodontia do ICS - Funorte/SoeBrás Núcleo Brasília; 2011.

\section{Endereço para correspondência:}

Ana Carolina Del-Sarto Azevedo,

Universidade Estadual do Sudoeste da Bahia -

Departamento de Saúde I

Av. José Moreira Sobrinho, $\mathrm{S} / \mathrm{N}$ - Jequiezinho, Jequié-BA

45206-190

Telefone: (73) 3528-9655

Email: acdelsarto@yahoo.com.br

Recebido: 30/10/2014. Aceito: 17/03/2015. 